\title{
Evaluation of dietary supplement use for the improvement of the condition of skin and its appendages
}

\author{
Katarzyna Korzeniowska', Artur Cieślewicz', Mariola Pawlaczyk², \\ Michał Pawlaczyk', Anna Jabłecka' \\ ${ }^{1}$ Department of Clinical Pharmacology, Poznan University of Medical Sciences, Poland \\ ${ }^{2}$ Department of Geriatric Medicine and Gerontology, Poznan Univerity of Medical Sciences, Poland \\ ${ }^{3}$ Department of Gynaecology and Obstetrics, District Hospital of Szamotuly, Poland
}

ABSTRACT

Introduction. The condition of skin, nails and hair depends on a diet. Proper diet ought to include all components necessary to ensure a well-balanced intake of proteins, fats, carbohydrates, vitamins and elements. Dynamic development of the dietary supplement industry offers an expanding range of products aimed to improve the condition of skin, hair and nails.

Aim. To study the issue of using dietary supplements aimed to improve skin and its appendages by men and women (in particular: studying the reason for such supplementation, determining the source of information about the supplements, evaluating the knowledge of the respondents and the effect of the supplements).

Material and methods. The questionnaire-based study was conducted in 2013-2014, in a group of 115 people (65 women and 50 men), aged 16-60 years, who had been using dietary supplements designed to ensure proper appearance of the skin, hair or nails. Statistical analysis was carried out using StatSoft Statistica 10.0 software.

Results. All participants had been using various dietary supplements for at least 4 months prior to the study commencement. $73 \%$ respondents declared that their main aim was to improve the condition of the skin, hair, and nails. The main reason for supplementation was the desire to improve the condition of the hair, reported by $48 \%$ of women and $64 \%$ of men. Both, women $(59 \%)$ and men $(48 \%)$ decided to supplement their diet mainly under the influence of the mass media. Considerable improvement in the condition of the skin and its appendages was observed by $79 \%$ of the respondents. Adverse effects were reported by $48 \%$ of the participants (with $72 \%$ concerning gastrointestinal tract).

Conclusions. 1. Information provided by the mass media remains the main cause of purchase and consumption of dietary supplements. 2. Subjective efficiency of supplementation has been confirmed by the majority of the respondents. 3. Approximately half of the studied population reported adverse effects, especially on the gastrointestinal tract.

Keywords: diet, dietary supplement, skin condition.

\section{Introduction}

The condition of the skin, nails and hair is largely dependent on a diet. It has been common knowledge for many years that a proper diet ought to include all components necessary to ensure a well-balanced intake of proteins, fats, carbohydrates, vitamins and elements [1-6].
According to the results of a CBOS (Centrum Badania Opinii Społeczneh - Public Opinion Research Center) survey, published in 2010, a vast majority of the Polish population considers themselves to be eating healthy [7]. Meal quality has been the focus of a number of surveys on nutrition and food. Regardless, Polish people 
continue to eat large amounts of meat, while fruit and vegetables are still treated as secondary components of everyday diet [8]. Thus, traditional Polish diet does not ensure proper supply of all necessary ingredients [9]. Lack, deficiency or excess or particular elements may result in serious health consequences [10-12].

The mass media have been portraying the feminine and masculine ideal as forever young and beautiful. Thus, an average consumer often associates dietary supplements with health and healthy lifestyle. The Food Act of 25 August, 2006 on food and nutrition safety, defines dietary supplements as "concentrated sources of nutrients or other substances with a nutritional or physiological effect whose purpose is to supplement the normal diet. They are marketed 'in dose' form (...), excluding medicinal products according to pharmaceutical laws and regulations" [13].

Dynamic development of the dietary supplement industry offers an expanding range of products which, according to the producers, improve the condition of the skin, hair and nails [14, 15].

\section{Aim}

The aim of the article was to study the reason for using supplements that have beneficial effect on skin and its appendages, to determine the source of information about the supplements, and to evaluate the knowledge of the respondents and the effect of the supplements.

\section{Material and methods}

The questionnaire-based study was conducted in 20132014, in a group of 115 people (65 women and 50 men), aged $16-60$ years, who had been using dietary supplements which, according to manufacturers, have been designed to ensure proper appearance of the skin, hair or nails. The questionnaire was designed especially for the purpose of the study and comprised two parts. The first part allowed to characterize the respondents in terms of age, sex, place of residence, anthropometric indices and diet. The remaining questions referred to their knowledge about dietary supplements, reasons for their use, benefits and safety. The questionnaire mostly consisted of closed questions, with one-choice or multiple-choice answers.

Statistical analysis was carried out using StatSoft Statistica 10.0 software. Crosstabulation tables and Pearson's chi-squared test (with $p=0.05$ as statistical significance threshold) were used to evaluate statistically significant differences between men's and women's answers.

\section{Results}

All participants had been using various dietary supplements for at least 4 months prior to the study commencement. Approximately $73 \%$ of the respondents declared that their main aim was to improve the condition of the skin, hair, and nails (Figure 1). According to their subjective opinions, the vast majority of the respondents (78\%) perceived their diet so far as rational. Therefore, only $9 \%$ of the subjects aimed to supplement their diet, while 18\% followed recommendations of their doctor, dietician or pharmacist. All respondents reported a pharmacy to be the only place where the supplements were purchased. Use of more than one supplement was declared by 29 (36\%) participants.

The main reason for supplementation was the desire to improve the condition of the hair, reported

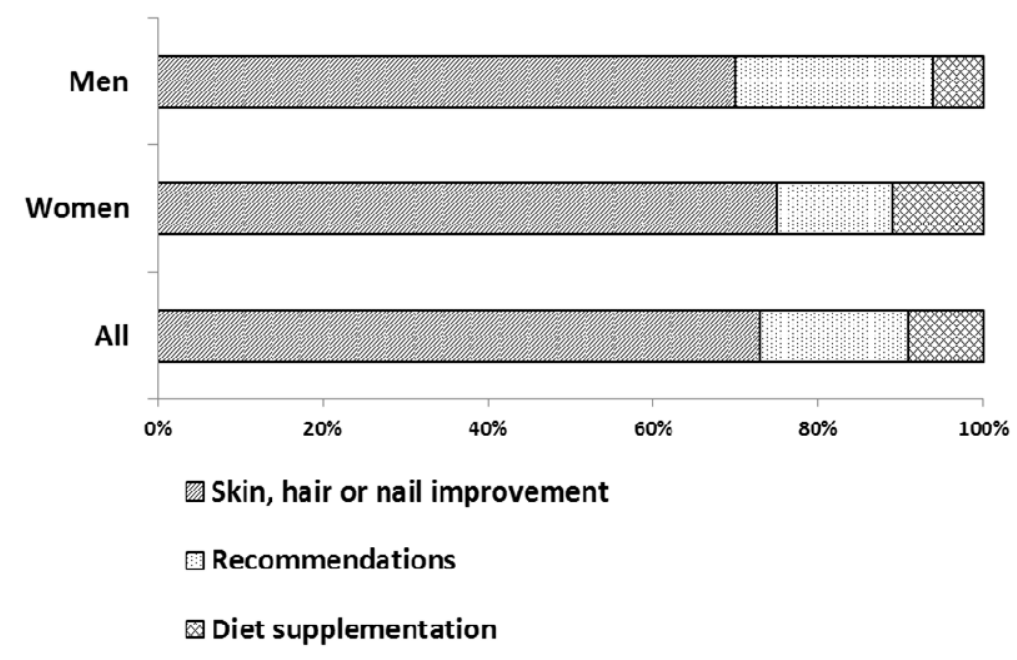

Figure 1. Reasons for supplementation 
by $48 \%$ of women and $64 \%$ of men. The second reason was different in men (improvement of skin - 30\% of respondents) and women (improvement of nails 37\%) (Figure 2). The differences were statistically significant ( $p<0.001$; Table 1).

The respondents used dietary supplements of varying quality and quantity composition. According to the manufacturers, the supplements were combinations of vitamins $A, C, E, B_{1}, B_{2}, B 5, B_{6}, B_{12}$, PP, biotin, folic acid, $\beta$-carotene, plant extracts such as bottlebrush, millet, bread wheat, proteins including collagen, elastin, lactoferrin, trace elements: magnesium, iron, selenium, zinc, calcium, iodine, amino acids, mainly cysteine, methionine and fatty acids.
Both, women (59\%) and men (48\%) decided to supplement their diet mainly under the influence of the mass media: press, radio, TV and Internet. None of the women declared to follow the advice of a dietitian (Figure 3).

As far as the definition of a dietary supplement was concerned, $72(63 \%)$ of the respondents were not able to give a correct definition, whereas 37 (32\%) did not know it at all. A vast majority of study participants (61\%) evaluated their own knowledge about dietary supplements as "average" (Figure 4). Women's knowledge appeared to be greater than men's - this difference was statistically significant $(<0.05$; Table 1).

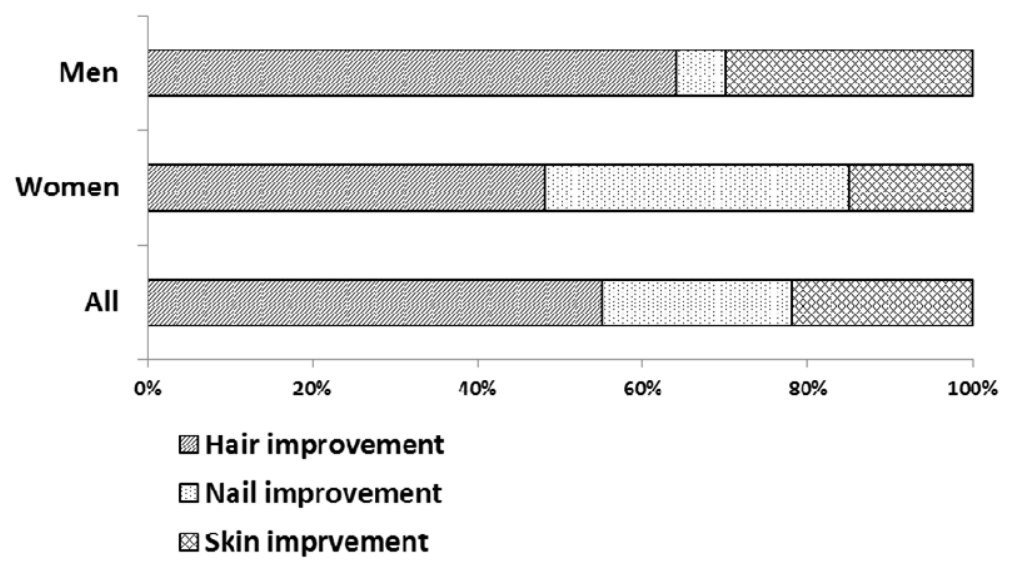

Figure 2. Indications for supplementation

Table 1. Statistical analysis of differences in men's and women's answers

\begin{tabular}{lc}
\hline \multicolumn{1}{c}{ Analyzed parameter } & $p$ \\
\hline Reasons for supplementation & 0.2942 \\
\hline Indications for supplementation & $0.0004 * *$ \\
\hline Sources of information & 0.0509 \\
\hline Knowledge about the definition & $0.0109 *$ \\
\hline Effect of dietary supplements & 0.4210 \\
\hline${ }^{* *} p<0.001,{ }^{*} p<0.05$ &
\end{tabular}

Men

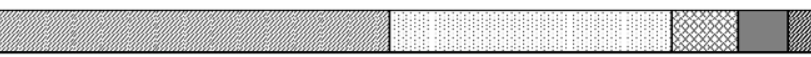

Women

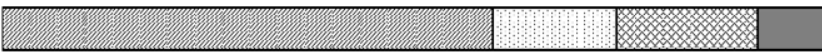

All

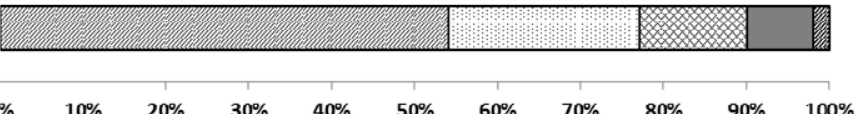

Mass media

THealth care worker

Beautician

$\square$ Friends

\section{面 Dietician}

Figure 3. Sources of information that inspired the decision of supplementation 
As far as the effects of diet supplementation were concerned, 91 (79\%) respondents noticed a considerable improvement in the condition of the skin and its appendages, 20 (17\%) found it challenging to assess the efficiency of supplements use, and only 4 (3\%) were dissatisfied with these products (Figure 5).

The use of dietary supplements according to manufacturer's recommendations was declared by 91 (79\%) of the respondents, while 101 (88\%) did not exceed the daily recommended dose. A total of 104 (90\%) study participants were of the opinion that dietary supplements were entirely safe for their health, basing that view on the conviction that an advertised and nonprescription product cannot possibly constitute a threat to life and health. Thus, only 45 (39\%) respondents paid attention to the information in the patient leaflet or the label of dietary supplements. Adverse effects were reported by 55 (48\%) participants, with $72 \%$ of them reporting gastrointestinal tract complaints (diarrhea, constipation, nausea). Headaches and skin reactions were observed significantly less frequently $(7 \%$ and $3 \%$, respectively).

Statistical analysis revealed that both men and women gave similar answers. Statistically significant difference was observed only for the question concerning the knowledge about the definition of a dietary supplement (Table 1).

\section{Discussion}

The range of dietary supplements has been developing dynamically in Poland as well as worldwide. Their diversified composition allows to use the products in different populations - children, seniors or the sick. In 2009 alone, the Chief Sanitary Inspectorate was notified about a record number of market introductions (1900) of dietary supplements [16].

Their development remains to be high, even exceeding the so-called "over-the-counter" medicines. According to experts, ageing society, growing interest

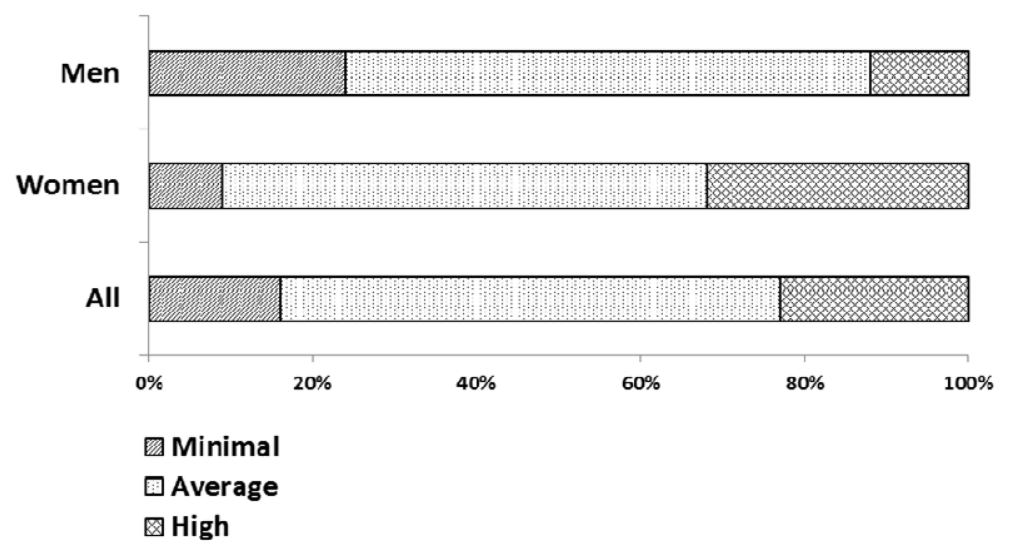

Figure 4. Evaluation of knowledge about the definition of a dietary supplement

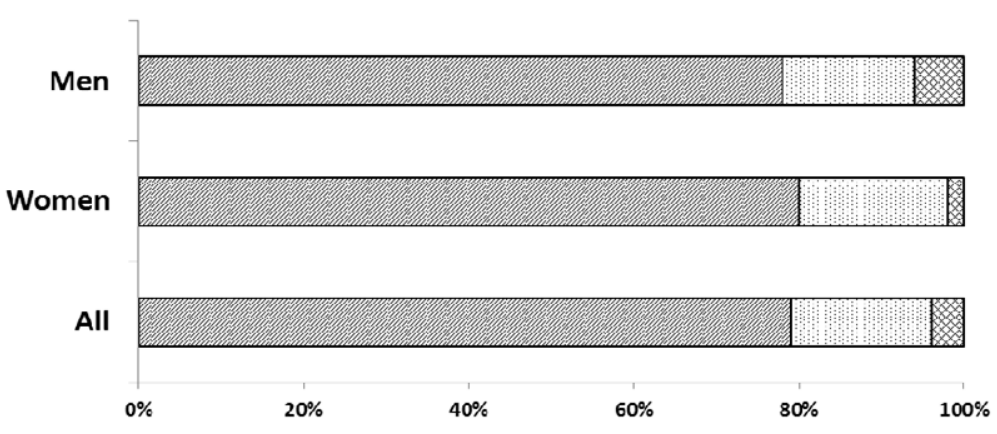

Definite improvement

\section{] Hard to say}

圆 No improvement

Figure 5. Evaluation of the effect of dietary supplements on the improvement in skin, hair, and nail condition 
in the area of self-healing, healthy lifestyle and appearance, as well as ecological and herbal products, will have a positive effect on the sales of dietary supplements [17-19].

An average consumer perceives the pharmaceutical market as a collection of a wide range of products which seem to be medicinal products or are, in fact, medicines. The place where they are purchased remains to be of great importance to the consumers, as well. They consider a pharmacy to be a reliable and safe source, which was confirmed by our findings that over $90 \%$ of the respondents found their products to be safe due to the fact they were available in pharmacies. Knowledge and understanding of a definition of a given product was of secondary importance - $32 \%$ of the respondents did not know the definition of a dietary supplement, while $63 \%$ were unable to recall the correct one, which in no way influenced their selfevaluation of knowledge about the issue. A vast majority $(61 \%)$ of the subjects subjectively assessed their knowledge about dietary supplements as "average".

Media have played a significant role in shaping attitudes to numerous areas of life, including appearance or eating habits. Press, radio, TV and the Internet remain to be the main source of information, also about medicine-related topics, for many Polish people. Quite often, it is the content of an advertising message that significantly influences the decision whether or not to buy a given product - be it a medicine or dietary supplement. For example, it was confirmed by Conner et al. [20].

Over $50 \%$ of study participants identified the mass media as the stimulus behind the decision to use dietary supplements. In light of the fact that dietary supplements are commonly available outside a pharmacy, e.g. in the Internet stores, the process of educating consumers how to distinguish between medicinal products and supplements, or other products, is vital [21].

A great number of people turn to the Internet in search of information on the effectiveness of dietary supplements. Alas, they are limited or scarce when it comes to the possibility of adverse effects. Thus, it is essential to expand the knowledge of the consumers both on the positive and negative consequences of supplementation as well as to educate them about proper food-related behaviors [22].

Statistical analysis showed that for men the most important indicator for starting supplementation was condition of hair and skin while for women - hair and nails. Women also evaluated their knowledge on discussed supplements better than men.

\section{Conclusions}

1. Information provided by the mass media remains the main cause of purchase and consumption of dietary supplements aiming to improve the condition of the skin, hair and nails.

2. Subjective efficiency of supplementation has been confirmed by the majority of the respondents.

3. Despite the positive opinion about the safety of dietary supplements, approximately half of the studied population reported adverse effects, especially on the gastrointestinal tract.

4. Statistically significant differences between men's and women's answers were found in issues concerning the reason of supplementation and knowledge on the supplements.

\section{References}

1. Draelos ZD. Aging skin: the role of diet: facts and controversies. Clin Dermatol. 2013;31(6):701-706.

2. Jeruszka-Bielak M, Brzozowska A. Relationship between nutritional habits and hair calcium levels in young women. Biol Trace Elem Res. 2011;144(1-3):63-76.

3. Liakou Al, Theodorakis MJ, Melnik BC, Pappas A, Zouboulis CC. Nutritional clinical studies in dermatology. JDrugs Dermatol. 2013;12(10):1104-1109.

4. Vranesić-Bender $D$. The role of nutraceuticals in antiaging medicine. Acta Clin Croat. 2010;49(4):537-544.

5. Wojtyła-Buciora P, Stawińska-Witoszyńska B, Klimberg A, Wojtyła A, Goździewska M, Wojtyła K, Piątek J, Wojtyła C, Sygit M, Ignyś I, Marcinkowski JT. Nutrition-related health behaviours and prevalence of overweight and obesity among Polish children and adolescents. Ann Agric Environ Med. 2013;20(2):332-340.

6. Zouboulis CC, Makrantonaki E. Clinical aspects and molecular diagnostics of skin aging. Clin Dermatol. 2011;29(1):3-14.

7. Behavior and dietary habits of Polish people. BS/150/2010 (in Polish). Available from http://www. cbos.pl/SISOMPOL/2010/K_150_10.PF

8. Szczepańska E, Deka M, Całyniuk B. Studies to determine nutrition behaviour amongst middle school pupils living in the border areas of Poland and the Czech Republic. Rocz Panstw Zakl Hig. 2013;64(3):191-196.

9. Anyżewska A, Wawrzyniak A, Woźniak A, Krótki M, Górnicka M. Nutritional assessment in Polish men with cardiovascular diseases. Rocz Panstw Zakl Hig. 2013;64(3): 211-215.

10. Lakdawala N, Babalola O. $3^{\text {rd }}$, Fedeles F, MCusker M, Ricketts J, Whitaker-Worth D, Grant-Kels JM. The role of nutrition in dermatologic diseases: facts and controversies. Clin Dermatol. 2013;31(6):677-700. 
11. Neufeld LM, Cameron BM. Identifying nutritional need for multiple micronutrient interventions. J Nutr. 2012;142(1):166-172.

12. Ramsey R, Giskes K, Turrell G, Gallegos D. Food insecurity among adults residing in disadvantaged urban areas: potential health and dietary consequences. Public Health Nutr. 2012;15(2):227-237.

13. The Food Act of 25 August, 2006 on food and nutrition safety (in Polish). Available from http://isap.sejm.gov.pl/ Download?id=WU20061711225\&type $=3$

14. Dietary Supplements. Available from http://www.fda. gov/food/dietarysupplements

15. Dietary Supplements: MedlinePlus. Available from http:// www.nlm.nih.gov/medlineplus/dietarysupplements.html

16. Krogulec W, Baran-Cwirta L, Majcher K, Radwanski M, Slugocka-Krupa E, Podgorski K. Bulletin of the Consumer Attorneys. 2011;2:7-12.

17. Bailey RL, Gahche JJ, Thomas PR, Dwyer JT. Why US children use dietary supplements. Pediatr Res. 2013. doi: 10.1038/pr.2013.160.

18. Gahche J, Bailey R, Burt V, Hughes J, Yetley E, Dwyer J, Picciano MF, MDowell M, Sempos C. Dietary Supplement Use Among US. Adults Has Increased Since NANS II (1988-1994). NHSData Brief No. 61 April 2011.
19. Molinero O, Márque S. Use of nutritional supplements in sports: risks, knowledge, and behavioural-related factors. Nutr Hosp. 2009;24:128-134.

20. Conner M, Kirk SF, Cade JE, Barrett JH. Why do women use dietary supplements? The use of the theory of planned behavior to explore beliefs about their use. Social Science \& Medicine. 2001;52(4):621-633.

21. Cellini M, Attipoe S, Seales P, Gray R, Ward A, Stephens $M$, Deuster PA. Dietary supplements: physician knowledge and adverse event reporting. Med Sci Sports Exerc. 2013;45(1):23-28.

22. Liu RH. Health-promoting components of fruits and vegetables in the diet. Adv Nutr. 2013;4(3):384S-392S.

Correspondence address: Katarzyna Korzeniowska Zakład Farmakologii Klinicznej 1/2 Długa Str., 61-848 Poznań, Poland phone: +48 618533161, +48618549000 fax: +48 618533161 email: zakladfarmakologiiklinicznej@ump.edu.pl 